Aus dem Anatomischen Institut der Med. Fakultät, Univ. Okayama

(Vorstand: Prof. M. SEKI).

\title{
Vergleichende Beobachtung der beiden Musculi recti bulbi temporales und Fasciculi optici der Maus nach einem einseitigen Augenverschluß.
}

\section{二十日鼠の片眼閉鎻後の両側の外側㨁筋と視束の比較観察.}

\author{
Ayame ISHII 石井葛 蒲.
}

[Eingegangen am 9. Juni 19.53.]

Messungen über die Dícke der Fasern der Orbitalmuskeln liegen durch Arbeiten von HALBAN (1894), SCHIEFFERDECKER (1927), KOHASHI (1937), KATO (1938) und HIRAI (1943) u. a. vor. OTSUKI (1950) hat den Bau der Orbitalmuskeln des Augapfels von Rind und Ratte, von Tieren sehr verschiedener Körpergröße, vergleichend untersucht. Es wurde in vorliegender Arbeit die Dicke der Fasern der beiden Musculi recti temporales und Fasciculi optici von Mäusen nach einem Verschluß des einseitgen Auges auf längere Zeit untersucht.

\section{Material und Methode.}

Bei neugeborenen Mäusen wurde das rechte Auge gleich nach der Öffnung wieder durch eine Naht verschlossen, wie ich in der vorigen Miteilung (1953) besprochen habe. Die so operierten sechs Tiere wurden im Alter von 45 bis 120 Tagen getötet. Die Augäpfel wurden mit dem lateralen geraden Augapfelmuskel in situ mit Bichromat-Formalinlösung fixiert. Für die Einbettung in Celloidin wandte man die Methylalkohol-Celloidinmethode von SEKI (1937) an, wobei das Celloidin verhältnismäBig leicht in das Objekt eindringt und Schrumpfungen der Gewebe vermieden werden. $15 \mu$ dicke Querschnitte wurden aus der Grenze von ursprünglichem und mittlerem Drittel des genannten Muskels verfertigt und nach HEIDENHAIN mit Eisenhämatoxylin gef ärbt. Die Querschnitte von 200 Muskelfasern wurden mit Hilfe eines Zeichenapparates in 1,000maler Aergrößung bezeichnet und mit dem Planimeter gemessen. Die erhaltenen Werte sind in Tabelle leinfachheitshalber in 1/100 verkleinert dargestellt.

Der Fasciculus opticus wurde den 5 Mäusen mit einem versehlossenen Auge im Alter von 54 bis 72 Tagen entnommen, in der mit Osmiumsäure zugesetzten MÜLLERschen Flüssigkeit fixiert und in Celloidin eingebettet. Die. Querschnitte von $15 \mu$ Dicke aus dem vorderen Ende des Sehbündels ließen sich nach der PALschen Markscheidenfärbungsmethode färben. Man bezeichnete die Querschnitte in 200maler Vergrößernng und maß sie mit 
dem Planimeter.

\section{Ergebnisse der Messung.}

\section{a) Musculus rectus temporalis.}

Die gefundenen durchschnittlichen Werte mit $\sigma$ und $\mathrm{V}$ finden sich in Tabelle 1. Nur bei einer 94 Tage alten Maus ist die Dicke der Fasern auf den beiden Seiten gleich, bei den übrigen sind aber immer die Muskelfasern des rechten verschlossenen Auges dicker als die des linken Auges. Bei dem verschlossenen Auge sind die Standardabweichung $\sigma$ und der Variationskoeffizient $\mathrm{V}$ fast immer größer, d. h. die Muskelfasern sind bei ihm in größerem Maße von ungleicher Dicke.

Tabelle 1. Dicke der Muskelfasern des Musculus rectus temporalis $\left(\mu^{2} / 100\right)$.

\begin{tabular}{c|c|c|c|c|c|c}
\hline $\begin{array}{c}\text { Tage } \\
\text { N. d. } \\
\text { Geburt }\end{array}$ & \multicolumn{3}{|c|}{ Linkes Auge } & \multicolumn{2}{c}{ Rechtes verschlossenes Auge } \\
\cline { 2 - 7 } \cline { 5 - 7 } & $\mathrm{M} \pm \mathrm{m}$ & $\sigma$ & $\mathrm{V}$ & $\mathrm{M} \pm \mathrm{m}$ & $\sigma$ & $\mathrm{V}$ \\
\hline 45 & $2.44 \pm 0.09$ & 1.26 & 51.7 & $2.94 \pm 0.11$ & 1.52 & 51.6 \\
47 & $2.08 \pm 0.05$ & 0.67 & 32.4 & $2.10 \pm 0.06$ & 0.83 & 39.6 \\
59 & $1.61 \pm 0.05$ & 0.75 & 46.7 & $2.35 \pm 0.10$ & 1.38 & 59.0 \\
74 & $2.65 \pm 0.07$ & 0.95 & 35.7 & $3.31 \pm 0.13$ & 1.88 & 57.0 \\
94 & $2.42 \pm 0.09$ & 1.31 & 54.1 & $2.63 \pm 0.09$ & 1.28 & 48.6 \\
120 & $2.44 \pm 0.08$ & 1.08 & 44.1 & $2.99 \pm 0.14$ & 1.92 & 64.2
\end{tabular}

Das Auge der Maus kann sich einzeln bewegen, ohne da $B$ es mit dem ander seitigen kombiniert. Der Augapfel des rechten verschlossenen Auges hatte sich a'so im Vergleich zu dem anderseitigen weniger bewegt. Nawh der Untersushung von HIRAI (1943) an den ganzen Körpermuskeln, einschlieB'ich der Orbitalmuskeln, des Wild- und Hauskaninchens sind die Muskelfasern beim sich lebhaft bewegenden Wildkaninchen fast ohne Ausnahme dünner a!s beim Hauskaninchen, beim ersteren ist ferner in den Muskeln das interstitie!le Bindegewebe reichlicher zu sehen. Das Gleiche gilt auch für die lateralen geraden Augapfelmuskeln aus den natürlichen und vernähten Augen.

b) Fasciculus opticus.

Tabelle 2. Dicke des Fasciculus opticus (qmm).

\begin{tabular}{c|c|c}
\hline $\begin{array}{c}\text { Tage n. d. } \\
\text { Geburt }\end{array}$ & Linkes Auge & $\begin{array}{c}\text { Rechtes } \\
\text { verschl. Auge }\end{array}$ \\
\hline 54 & 0.061 & 0.055 \\
61 & 0.053 & 0.044 \\
65 & 0.044 & 0.039 \\
67 & 0.061 & 0.047 \\
72 & 0.080 & 0.062
\end{tabular}

Die Resultate sind in Tabelle 2 zusammengestellt. Man ersieht, daß das Sehbündel sich unter Lichtabschlu B schlechter entwickelt. Im feineren Bau wurden aber keine Unterschiede gefunden. 
Zu bemerken ist hierzu die Arbeit von BER xER (1900). Er verschloB die beiden Augen von Hund und Katze kurz nash der Geburt. Die so operierten Jungen wurden mit den anderen von demselben Wurf 87 bis 294 Tage am Leben gelassen. Im Fasciculus opticus traten aber dabei keine nachweisbaren Entwicklungshemmungen auf, trotzdem deutliche Entwicklangshemmungen in der Grsßhirnrinde erkennbar waren.

\section{Zusammenfassung.}

Der im Titel genannte Muskel und Bündel von Mäusen, die mit einem künstlich verschlossenen Auge 45 bis 120 Tage lebten, wurden untercht. Der Muskel des verschlossenen Auges zeigte fast ohne Ausnahme durchschnittlich dickere Fasern. Die Dicke der einzelnen Fasern variierte bei ihm etwas mehr. Das Sehbündel von dem unbelichteten Auge war immer dünner.

\section{內 容自抄。}

1 眼を閏鎻し，光を遮断した二十日鼠の雨眼の外側直筋筋線維と視束を 測定し，閉顉された側の外側直笳の筋線維は殆んど例外なく他側のものよ り平均して太く, 個队の線維の太さに変異がやや多く, 視束は比較的細い ことが見られた。

\section{Literatur.}

Berger, H.: Experimentell-anatomische Studien über die durch den Mangel optischer Reize veranlassten Entwicklungshemmungen im Occipitallappen des Hundes und der Katze. Arch. Psychiatr. 33 (1900) - Halkan, J.: Die Dicke der quergestreiften Muskelfasern und ihre Bedeutung. Anat. H. 3 (1894). Hirai, T.: Vergleichende histologische Untersuchungen der Skeletmuskeln des Haus- und Wildkaninchens. Fol. anat. jap. 22 (1943). - Kato, T.: Über histologische Untersuhung der Augenmuskeln von Menschen und Säugetieren. Fol. anat. jap. 16 (1938). - Kobashi. Y.: Histolgische Untersuchungen der verschiedenen Skeletmuskeln beim Menschen. I. Fol. anat. jap. 15 (1937). Oisuki, M.: Vergleichung des Baues der Orbitalmuskeln von Rind und Wasserratte. Arch. hist. jap. 1 (1950). - Schief ferdecker, P.: Vergleichende Betrachtungen über 116 von mir untərsuchte Muskeln. Z. mikrosk. -anat. Forsch. 9 (1927). - Seki, M.: Untersuchungen mit nichtwässerigen Flüssigkeiten. III. Erfahrungen auf dem Gebiet der Celloidineinbettung. '/. Zellforsch. 26 (1937). 